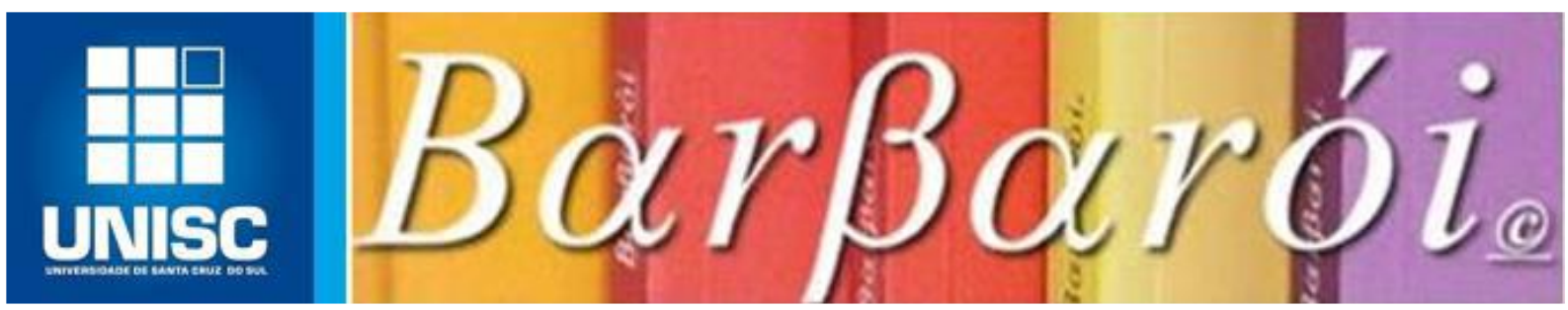

\title{
UMA PROPOSTA HISTÓRICO-CULTURAL DO FAZER CLÍNICO: RELATO DE EXPERIÊNCIA EM OFICINAS TERAPÊUTICAS
}

\author{
DOI: http://dx.doi.org/10.17058/barbaroi.v0i0.14744 \\ $*$
}

Gilson Gomes Coelho

Faculdade Católica Dom Orione - FACDO - Brasil

Ana Carolina Carvalho Arruda

Faculdade Católica Dom Orione - FACDO - Brasil

Anna Lícya Ferreira Carneiro

Faculdade Católica Dom Orione - FACDO - Brasil

Eliane Soares Lima

Faculdade Católica Dom Orione - FACDO - Brasil

João Henrique Oliveira Barros

Faculdade Católica Dom Orione - FACDO - Brasil

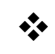

\section{Resumo}

Este trabalho trata-se de um registro teórico-prático, descritivo e qualitativo, referente a experiência de Estágio Básico em Psicologia Clínica, da Faculdade Católica Dom Orione. O mesmo ocorreu nas dependências de um Centro de Atenção Psicossocial Infanto-Juvenil (CAPSi). O estágio referido foi realizado através de observações em oficinas terapêuticas, com público alvo de adolescentes, teve como principal intuito favorecer a constituição de vínculos entre estagiários, mediadores das oficinas, adolescentes usuários e familiares, levantando as principais demandas ali expostas, e conseguinte elaborar ações de acordo com os embasamentos teóricos da abordagem histórico-cultural, articulando teoria e prática, aspirando a materialização das emoções e vivências do grupo acompanhado, bem como compreender o processo de subjetividade dos adolescentes a partir de um fazer psicológico para além da clínica. No decorrer das observações foi compreendido que existe um distanciamento entre o serviço ideal e o que é ofertado, tornando factível a correlação entre teoria e prática do psicólogo dentro da instituição, considerando que se faz necessário suscitar reflexões respaldadas em experiências pertinentes às ações desenvolvidas nestes espaços, que tem como projeto um novo modelo de saúde mental, com o propósito de promover um serviço cada vez mais pautado na ética, no respeito e no compromisso social e político, com vistas a reivindicar o direito das pessoas a um serviço cada vez mais preparado para acolher as necessidades individuais de cada um, visando sempre a promoção de saúde.

Palavras-chave: Oficinas Terapêuticas. Adolescentes. Histórico-Cultural.

Barbarói, Santa Cruz do Sul, n. 56, p.<223-245>,jan./jun. 2020 


\section{Introdução}

A experiência do estágio é essencial para o processo de formação, considerando que um preparo de qualidade exige a articulação entre teoria e prática, levando os educandos a experienciar a prática, a partir do contato com a realidade da população e da instituição, além de desenvolver habilidades e competências para atuação no mercado de trabalho, a partir de um prisma crítico e reflexivo. Santos e Nóbrega (2017) relatam que esse processo auxilia na estruturação da consciência crítica, de forma que a consciência reconfigura a atividade, corroborando em outras reflexões e capacidades de ações que delineiam o processo de consciência, apoiado para uma formação mais crítica e contextualizada com a realidade sociocultural, proporcionado uma percepção mais articulada, suplantando a neutralidade dos currículos tradicionais.

Em harmonia com Mafuani (2011), ao adentrar na universidade, o educando se depara com o conhecimento teórico, mas muitas vezes é difícil fazer a inter-relação do mesmo se o estudante não vivenciar momentos reais em que será preciso analisar o cotidiano. De acordo com a lei que regulamenta o estágio, lei n. ${ }^{\circ}$ 11.788/2008, o estágio é de grande relevância na formação do discente, pois proporciona o aprendizado de habilidades inerentes da atividade profissional e a contextualização da matriz curricular do curso, visando possibilitar o crescimento e aperfeiçoamento do aluno para a vida e para o mercado de trabalho.

Para a Psicologia, segundo a Carta de serviços sobre estágios e serviços-escolas - CFP (2013), o estágio tem por objetivo aprimorar o exercício profissional e sociocultural, oferecendo ao educando a oportunidade de vivenciar e problematizar a realidade, sendo ambiente propício para atividade profissional supervisionada, para levantamento de demandas, pesquisas e intervenções em novas áreas de atuação.

Este trabalho trata-se de um estudo descritivo e qualitativo, construído a partir das vivências do Estágio Básico Supervisionado em Psicologia Clínica, realizado nos meses de agosto a dezembro de 2019, em um Centro de Atenção Psicossocial Infanto-Juvenil (CAPSi). De acordo com Leal e Delgado (2007), o CAPSi, refere-se a um espaço caracterizado como dispositivo que objetiva superar a lógica hospitalocêntrica concernente à política pública de assistência à saúde mental, promovendo a desinstitucionalização dos corpos, se desvinculando assim da lógica manicomial.

Durante o período de execução do referido estágio, foram realizadas observações em oficinas terapêuticas com adolescentes, objetivando elencar as demandas predominantes do grupo e assim traçar atividades a partir dos pressupostos teóricos da abordagem históricocultural, visando a materialização dos sentimentos dos participantes do grupo.

Barbarói, Santa Cruz do Sul, n. 56, p.<223-245>,jan./jun. 2020 


\section{Marco teórico}

Desde o início dos tempos, percebe-se que o homem busca apresentar respostas explicativas acerca da sua existência, os fenômenos que formam a si e a sua realidade, assim como as relações daí oriundas. Essas buscas de respostas existenciais foram trilhadas por inúmeros estudiosos, sempre no intuito de elencar explicações convincentes a respeito do funcionamento do universo e da vida humana nas suas particularidades mais complexas. A Psicologia enquanto ciência que se ocupa da investigação, análise e compreensão dos fenômenos humanos também buscou trazer sua contribuição, no intuito de alcançar uma explicação para os processos constituintes do homem e suas relações. Ao olhar a psicologia a partir de uma perspectiva histórico-cultural, é possível assimilar a sua formação como ciência e assim entender seus debates atuais acerca das relações sociais desenvolvidas pelos homens (CASTRO, 1997).

Ainda de acordo com o autor mencionado anteriormente, a psicologia enquanto campo teórico e científico destina-se a entender as ações, atitudes e comportamentos humanos a partir da dinâmica social alicerçado das relações entre os homens. As pesquisas acerca da história social dos indivíduos se deram inicialmente por volta da década de 50 e 60 , que foram marcadas pelo apogeu do estruturalismo ${ }^{1}$, pelas contribuições marxistas e também pelas ciências sociais.

A partir desse contexto surge na União Soviética um grupo de pesquisadores formados por Alexander Romanovich Luria e Alexei Nikolaievich Leontiev, liderados por Lev Semenovich Vygotsky com vistas a propor a Psicologia histórico-cultural como proposta teórica e metodológica (BORTOLANZA E RINGEL, 2016), no intuito de superar as visões dicotômicas e reducionistas das demais abordagens acerca da concepção de homem, bem como trazer à tona um método de investigação reflexivo e crítico, a fim de analisar e compreender as questões relacionadas a cultura, a história e as relações dos indivíduos.

Conforme apontado por Sirgado (1990), Vygotsky, Luria e Leontiev trouxeram enormes contribuições no que diz respeito a Linguística, Psicologia, Pedagogia e Neurologia em um momento crítico em que a Psicologia encontrava-se voltada para o experimentalismo, enfatizando o papel de elementos como a cultura e a linguagem no desenvolvimento das funções psicológicas superiores - atividades mentais construídas via cultura e sociedade como a

\footnotetext{
${ }^{1} \mathrm{O}$ estruturalismo foi um movimento intelectual de grande valia para a revolução científica da filosofia e das ciências humanas. Atualmente é visto como uma linha de pensamento, bem como uma posição científica geral para todos os campos do conhecimento humano. Compreende o estudo do homem em sua criação cultural,assim como, o estudo da linguística (CÂMARA JR, 1967).
}

Barbarói, Santa Cruz do Sul, n. 56, p.<223-245>,jan./jun. 2020 
memória, raciocínio, pensamento, atenção, emoção e pensamento - no intuito de tornar a Psicologia mais geral e unificada.

A psicologia histórico-cultural tem como objetivo a busca de um modelo que elucida o funcionamento psicológico e a constituição do homem em seu processo histórico-cultural (PESSOA, 2015). Para tanto, fundamenta-se no marxismo e adota como filosofia, teoria e método o materialismo histórico dialético, que é uma teoria idealizada por Marx para pensar a sociedade com enfoque em pontos como: a coletividade, a contradição, a política, a história e a produção. Atribuindo ao homem um caráter ativo, social e histórico (BOCK, 2007).

Nesta proposta, Vygotsky (1989) assinala que a ontogênese ${ }^{2}$ humana não é pura e apenas uma história individual. O mesmo acredita que é uma reprodução da transformação da espécie, que foi ressignificada por intermédio da internalização subsequente da apropriação cultural. É a partir deste ponto de vista que o autor buscou inteirar-se basicamente em três pontos primordiais para a elaboração de sua teoria. O primeiro ponto se dava na compreensão da relação entre o homem e seus ambientes, buscando uma maior compreensão do homem enquanto ser biológico e ser social, isto é, enquanto membro da espécie humana e, ao mesmo tempo, participante de um processo histórico-social em constante transformação (VYGOTSKY, 1991; VYGOTSKY; LURIA, 1996); o segundo pautava-se na verificação de novas formas de atividades que fizeram com que o trabalho fosse o meio primordial da relação homem-natureza, complementando o ponto anterior; e o terceiro, os estudo dos instrumentos e da linguagem acerca das relações com a natureza (JOENK, 2002).

Como visto acima, os pontos apresentados por Vygotsky estão entrelaçados, permitindo uma análise íntegra acerca do homem social em todas as suas particularidades. É a partir deste entendimento e também do raciocínio do autor acerca de sua teoria, que o mesmo buscou elencar alguns conceitos que contribuíram para o embasamento da abordagem. Dentre os principais conceitos elucidados encontram-se: a mediação, a atividade, os signos e os instrumentos (OLIVEIRA, 1993).

Ainda de acordo com o autor, no que diz respeito ao conceito de mediação, é definido como um processo de intervenção de um componente entremeio numa relação. Vygotsky defende que o homem não tem acesso direto aos objetos, mas acessos mediados, por meio de recortes do real, operados pelos sistemas simbólicos de que dispõem. Em suma, o homem e sua relação com o mundo é sobretudo uma relação mediada. À vista disto, a mediação é a ideia

\footnotetext{
2 Designa o conjunto de processos de desenvolvimento do indivíduo desde a fecundação até à sua morte. Integra, em cada um dos seus momentos, os efeitos combinados e indissociáveis de maturação e da experiência, traduzindo, assim, a resultante das interacções genéticas e epigenéticas (MONTEIRO; TAVARES; MORENO, 2019).
}

Barbarói, Santa Cruz do Sul, n. 56, p.<223-245>,jan./jun. 2020 
central da concepção sobre o desenvolvimento humano como processo histórico-cultural, visto que, é nesse processo de mediação que as funções psicológicas superiores se desenvolvem (BERNI, 2006).

No que concerne ao conceito de instrumento, Fontana e Cruz (1997) o define como aquilo que se interpõe entre o homem e o ambiente, ampliando e modificando suas formas de ação. São elementos entre o sujeito e o objeto de ação que ampliam as possibilidades de transformação do meio social, funcionando com um objeto social mediador entre o sujeito e o mundo. A internalização, por sua vez, é dada através da mediação entre a atividade e o sistema de signos.

Dentre os sistemas de signos, a linguagem se configura como o signo mediador principal, pois é por intermédio da mesma que se fornece os conceitos, as formas de organização do real, a mediação entre o sujeito e o objeto do conhecimento. É com a linguagem que as funções psicológicas superiores se estabelecem (TULESKI, 2008).

Em meio as principais contribuições de Vygotsky, destacam-se os estudos acerca do pensamento e da linguagem, no qual o autor buscou elencar o percurso do desenvolvimento das operações mentais, utilizando-se dos princípios da teoria histórico-cultural. Vygotsky (1991) mediante as considerações ontogênicas, diz que a relação entre o pensamento e a linguagem percorrem juntas, mas possuem raízes diferentes, isto é, o pensamento diz respeito a imagens que o sujeito tem internalizadas, portanto existe uma conexão entre ambas.

Para entendermos, partimos do pressuposto de que a linguagem é um intercâmbio social, onde tem como principal objetivo a comunicação, no qual ela tem uma função de pensamento generalizante, que seria ela enquanto instrumento deste pensamento. É através da linguagem que a criança consegue modificar suas funções psicológicas superiores, dar forma delineada ao pensamento, facultando a manifestação da imaginação, o uso da memória e o planejamento da ação. Assim, segundo Azevedo (2007) “a linguagem é para nós o que a água é para o peixe; nossa vida social existe por causa da linguagem que desenvolvemos".

A partir deste entendimento acerca dos principais conceitos da perspectiva históricocultural, tem-se uma nova compreensão sobre o conceito de homem nesta abordagem, atribuindo a ele um caráter ativo, social e histórico. Vygotsky, ao analisar essa concepção, aponta que o homem assim como qualquer outro ser precisa estar em contínua transformação junto ao meio natural. Sem esse contato infindável com a natureza, habitual a todos os animais, o homem não seria capaz de obter os elementos fundamentais para o seu sustento e reprodução enquanto espécie. Todavia, para melhor compreensão deste homem mutável, se faz necessário, 
a priori, o entendimento sobre a consciência, bem como a subjetividade. Aspectos importantes que contribuem para a construção deste ser (MARX E ENGELS, 1999).

De acordo com Aguiar (2000), ao entender que o homem é um ser ativo, social, histórico e construtor da própria história percebe-se que este sujeito não se constitui com base em fenômenos internos, afirmando a passagem defendida pela histórico-cultural, onde a consciência se dá na passagem de fora para dentro, ou seja, a partir da representação do objetivo no subjetivo (LEONTIEV, 1978). Assim, a consciência diz respeito às formas de pensar, sentir e agir. Tendo como princípio a gênese social, pois resulta dos processos de internalização dos signos, sendo material importante para a compreensão do funcionamento do indivíduo. Assim, de acordo com o autor, ela é construída através do trabalho, das relações sociais e mediada através da linguagem (VYGOTSKY, 1989).

De acordo com Saviani (2004) no que concerne a subjetividade, a partir dos estudos de Marx, o conceito se dá por intermédio da lógica dialética que diz que "o conteúdo da essência humana reside no trabalho". O ser do homem, a sua existência, não é dada pela natureza, mas é produzida pelos próprios homens". Isto é, o homem evolui a partir da relação com outros homens por meio da linguagem, instrumentos mediadores e em situação de trabalho. Em síntese, Ferreira (2010) menciona que o homem aprende a ser homem.

A partir dessa perspectiva, Leontiev (1978/2004) compreende que a subjetividade está ligada com a singularidade do sujeito, aquilo que o torna único, uma formulação ímpar que designa a experiência vivida. Dessa forma, González-Rey, Goulart e Bezerra (2016) apontam que este fenômeno é possível através da mediação do mundo externo com o interno, que funciona a partir da dialética entre a objetividade e a subjetividade.

Essa dialética se dá mediante a estruturação das funções psicológicas superiores, que operam através da mediação dos signos, onde o autor considera que estas funções são de origens histórico-cultural, por se tratar da interação do sujeito com o social. Segundo Lucci (2006), apesar de tais funções terem berço na vida social e cultural do indivíduo, só é viável mediante a existência de atividades cerebrais, ou seja, as funções psicológicas superiores não são originadas do cérebro, mas não é possível a existência de tais sem o mesmo, visto que se operam das funções elementares que estão ligadas aos processos cerebrais (VYGOTSKY, 1996).

Em linhas gerais, Joenk (2002) alude que as funções psicológicas superiores juntamente com a consciência se desenvolvem a partir dos meios sociais, pois, o indivíduo em contato com a cultura utiliza-se de signos que vão influenciar diretamente na formação do psiquismo. Isto pode ser percebido durante o processo de desenvolvimento de um sujeito, onde o mesmo colhe as informações sociais através da mediação e assim os internaliza, fazendo com que Barbarói, Santa Cruz do Sul, n. 56, p.<223-245>,jan./jun. 2020 
determinado conteúdo passe a ter significado para o sujeito. Assim, percebe-se que a consciência se constrói progressivamente.

A partir desse raciocínio sobre a formação do homem, baseado no entendimento da consciência e da subjetividade, entende-se que o homem é instantaneamente um ser natural vivo, por isso está abastecido de influências naturais e indispensáveis. É um ser naturalmente dinâmico. Tais influências servem como oportunidades e competências, em contrapartida como ser vivo, físico, emotivo e racional, o mesmo também é um ser que possui limitações. Isso significa que o homem tem instrumentos eficazes, sensíveis como agentes de seu ser (MARX, 2004).

Partindo para uma perspectiva clínica a partir desta abordagem, percebe-se que a mesma ainda é uma prática recente no cenário brasileiro. Em conformidade com Marangoni e Aires (2006) essa nova alternativa visa expandir a perspectiva da prática clínica no tocante à compreensão do indivíduo, a interação de acontecimentos sociais, econômicos e políticos, bem como às concepções tradicionais das demais abordagens, abolindo a dicotomia objetividade/subjetividade e a patologização do indivíduo. Com isso retira-se do sujeito a ideia engendrada de que suas dificuldades individuais e/ou coletivas são motivadas intrinsecamente de forma isolada.

Desta forma, a partir dos estudos sobre a semiologia, Dalgalarrondo (2008) relata a importância dos signos e sintomas que são retratados pelo paciente dentro do setting terapêutico. $\mathrm{O}$ autor menciona que o signo ultrapassa a esfera da fala, ao considerar as inúmeras formas de signo, como gestos, atitudes, comportamentos não-verbais, dentre outros.

Para tanto, o psicólogo apropria-se do modelo clínico relacional dialógico aliado às teses de Vygotsky como prática interventiva, teorizando que a mudança via processos psicoterapêuticos resulta da relação entre terapeuta e paciente, por meio de recursos e instrumentos mediadores como a linguagem e as técnicas lúdicas (brincadeiras e desenhos). O método relacional dialógico diz respeito ao acesso da pessoa em sua totalidade psicológica, sociológica e emocional, agregando ainda o desenvolvimento psicomotor, cognitivo e social (BRÁS, 2013). Tal processo deve ser dinâmico-relacional, pois ao tempo em que depende de uma relação para acontecer, tem caráter dinâmico por envolver a participação ativa do sujeito no processo, com espaço para a associação livre, com foco no estudo das emoções e significados, atribuindo valor à característica relacional destas, entendendo que se trata de construções do indivíduo absorvidas via história de vida e cultura (DIAS, 2005).

Segundo González-Rey (2001) pode-se elencar como pontos primordiais que devem ser considerados na prática clínica histórico-cultural a subjetividade que é construída Barbarói, Santa Cruz do Sul, n. 56, p.<223-245>,jan./jun. 2020 
historicamente, o caráter singular do indivíduo, a consideração da subjetivação, dos sentidos e dos significados gerados nas relações, o reconhecimento do caráter constitutivo das patologias e o objetivo de se descobrir as configurações do sujeito, pois cabe ao terapeuta determinar os processos de sentido e de significado para a produção de novos sentidos de subjetivação, rompendo com processos de fragilização e construindo soluções para os conflitos. O psicólogo é, portanto, um mediador, construtor e facilitador de sentidos e de novas produções subjetivas.

A partir do momento em que se compreende que o homem não é um indivíduo isolado, tem-se que sua subjetividade é atravessada por inúmeros processos complexos de outras subjetivações. Sendo assim, não se pode reduzi-lo a uma organização única e padronizada. Trata-se de processo relacional e um emaranhado de diversas alternativas que acarretam inúmeras implicações para si. Essa flexibilidade da subjetividade é a mesma dos processos que se associam a sua constituição patológica (KAHHALE, 2003).

Tem-se assim um novo reconhecimento do caráter constitutivo das patologias. González-Rey (2011) aponta que os transtornos mentais não são uma doença biológica de fato, mas sim configurações subjetivas em processos da vida hodierna do sujeito, a qual são acrescentados mais sentidos subjetivos. À vista disso, nessa vertente clínica há uma preocupação em ultrapassar as classificações centradas na patologia, focando no trabalho psicoterapêutico.

Partindo desta perspectiva, González-Rey, Goulart e Bezerra (2016) debatem sobre a importância dos profissionais, principalmente da área da saúde, trabalharem ações voltadas para que novos ajustes relacionados a subjetividade aflorem, fazendo com que as pessoas se situem ativamente como sujeitos de suas experiências. Assim, não se trata de trabalhar apenas as causas externas que afligem o sujeito, mas de novas idealizações subjetivas que percorrem toda a vida do indivíduo.

Esses novos ajustes do indivíduo só são possíveis no plano das interações, um processo contínuo de troca e transformação. Nele os sistemas simbólicos, com ênfase na linguagem, são imprescindíveis na comunicação e na construção de novos significados e interpretações de objetos, eventos e situações no ambiente. Esse processo se materializa por meio de níveis adotados por Vygotsky. O sujeito apresenta um nível de desenvolvimento real, que inclui o conteúdo apreendido por ele durante os ciclos de desenvolvimento já percorridos. Esse nível vai de encontro ao desenvolvimento potencial, em que para a resolução de um problema ele precisa da assistência de um mediador mais experiente. Através do que já foi apreendido por ele, apropria-se de novos conteúdos via mediação, internaliza-os, constituindo uma nova consciência (LIMA E CARVALHO, 2013).

Barbarói, Santa Cruz do Sul, n. 56, p.<223-245>,jan./jun. 2020 
Ainda de acordo com o autor mencionado anteriormente, na prática clínica históricocultural, o grande diferencial é a zona de desenvolvimento proximal, que consiste em funções que estão em processo de amadurecimento. No que concerne às técnicas, é imprescindível atentar-se à realidade do sujeito e a maneira como ele percebe suas experiências, para desenvolver junto a ele nas sessões a zona de desenvolvimento proximal, ou seja, as capacidades emergentes, incorporando-as em seu nível de desenvolvimento real. Além disso, são importantes as técnicas de heterocronia, que se refere ao tempo que cada sujeito leva para internalizar novos conceitos; a instigação, que é o estímulo de novas potencialidades; a contextualização, que distribui em contextos os mitos adquiridos pelo sujeito durante a sua vida; e a despotencialização, que é a diminuição da potência de comportamentos ideais e fossilizados.

Além destas, Quintino-Aires (2011) e Marangoni (2012) trazem outras técnicas como a compreensão empática; a nomeação, que diz respeito à descrição e nomeação do acontecimento referido com vistas a produzir maior verbalização ou para proporcionar ao sujeito que ele se perceba através da fala do outro; a marcação, onde dá-se atenção a fala do outro, apoiando o diálogo sem interrupções; a generalização, que procura reduzir a ansiedade, demonstrando semelhança de determinada ação em outros humanos; eco-emocional, que auxilia o sujeito a dar nomes a emoções e a sentimentos caso seja difícil para ele fazê-lo; re-expressão, que descreve eventos apresentados pelo sujeito de forma racional e objetiva; e pôr-verbo, quando se descreve um comportamento quando não houve linguagem verbal (mais utilizada com crianças).

Partindo para o que concerne às contribuições da psicologia histórico-cultural para a categoria adolescência, Facci e Tomio (2009) apontam que esta nova abordagem a concebe como uma construção social, se desvencilhando das concepções naturalizantes e universais de outros especialistas e profissionais que a veiculam a uma etapa de desenvolvimento fruto apenas de amadurecimento biológico, com características pré-determinadas, que desconsideram o contexto social e histórico de cada indivíduo, atribuindo-lhes mudanças naturais e até patológicas de forma generalista.

Ainda de acordo com os autores mencionados anteriormente, tais mudanças são caracterizadas como tensões emocionais, rebeldia, contradições e enfrentamentos. A perspectiva trazida pela abordagem histórico-cultural visa compreender esta fase como fruto das condições materiais de produção, atrelada à história do desenvolvimento social do indivíduo, não a vendo e nem a institucionalizando como algo contínuo em que o comportamento se desenvolve de maneira gradual rumo à maturidade. 
A adolescência repercute diretamente na subjetividade e no desenvolvimento do homem contemporâneo. A sociedade é a figura de referência para a construção da identidade do jovem, pois significa, interpreta e constrói comportamentos que posteriormente serão internalizados, transformando-se em elementos individuais do sujeito. Trata-se da passagem de um círculo social restrito e primário que é a família para um universo mais amplo e secundário, o mundo afora. Vygotsky caracteriza esse desenvolvimento como um momento de formações e transformações qualitativas novas, com ritmo próprio, que requer mediações especiais, se constituindo em um processo dialético que envolve unidade psíquica, biológica e cultural (ALVES E CASSIM, 2017).

González-Rey (2011) defende que o aspecto basilar no trabalho clínico é a recuperação dos aspectos subjetivos no processo de adoecimento que vem a ser desconsiderados por um modelo biomédico atomista. A perspectiva de saúde, portanto, deve estar atrelada a qualidade dos processos de vida. Desta forma, o transtorno mental passa a ser visto não como doença de fato no sentido biológico, mas sim uma configuração subjetiva em processos temporâneos da vida do sujeito. Sendo assim, a Psicologia histórico-cultural carrega em si o cuidado de ir além das classificações, enquadramentos e patologizações. É reconhecido que as atividades e as relações do sujeito sempre encontrarão formas de subjetivação, ou de capacidade geradora.

Nesse sentido, é fundamental romper com as concepções naturalizadas e a-históricas de saúde, compreendendo que partimos de uma noção de saúde que se estabelece através do social, assim como pelas diferentes necessidades e pelos processos individuais que estão organizados nessa experiência, ou seja, trata-se de uma perspectiva histórico-cultural, que abarca de modo geral os aspectos sociais e individuais do sujeito, retratando as condições de sujeito dentro do processo saúde-doença (MORI E GONZÁLEZ-REY, 2012).

Dessa forma, segundo Nunes, Torres e Zanotti (2015) uma das maneiras de se trabalhar com os adolescentes são as oficinas terapêuticas, cerne do presente trabalho. Essas adquiriram uma nova perspectiva através da psiquiatra Nise da Silveira, em 1940, que atribuiu a elas um caráter terapêutico dentro da nova perspectiva assistencial no campo psiquiátrico, levantando também questões referentes aos desvios em sua utilização. Versava sobre a necessidade de a atividade ser realizada por livre e espontânea vontade, pois a partir do momento em que se dá uma participação obrigatória o objetivo terapêutico não é alcançado, ou seja, "a oficina se torna terapêutica para o usuário quando atende suas necessidades" (FARIAS et al. 2017).

Ainda de acordo com os autores mencionados anteriormente, nos Centros de Atenção Psicossocial Infanto-Juvenil (CAPSi), as oficinas terapêuticas se organizam sob critério de diagnóstico e idade, considerando os interesses individuais e o projeto terapêutico de cada um, Barbarói, Santa Cruz do Sul, n. 56, p.<223-245>,jan./jun. 2020 
e tem como objetivo promover a expressão da subjetividade, dos sentimentos e dos problemas dos usuários, incitando a convivência entre eles, a partir do diálogo e da interação, visando a construção de vínculos que permitem a troca entre profissionais e pacientes contemplando assim a integração social e familiar. Isso se dá por meio de atividades que envolvem trabalhos manuais, atividades de expressão, recreativas e culturais, como pinturas, músicas, danças, desde que tenham objetivos e significados, promovendo transformações em direção a autonomia do sujeito.

Entretanto, no que concerne às questões acerca da subjetividade no contexto saúdedoença, Guedes, Nogueira e Camargo Jr (2006) perceberam que ainda são pontos pouco discutidos, principalmente devido à prática médica optar por naturalizar a queixa levantada pelo sujeito, de modo a tentar ao máximo objetivar as práticas, aniquilando a subjetividade do sujeito em sofrimento. Dessa maneira, de acordo com algumas pesquisas realizadas para compreender esse processo, notou-se a existência de um desmembramento entre a teoria e as práticas médicas, que acabam por subdividir também o sujeito (objetividade x subjetividade).

Ainda de acordo com os autores mencionados anteriormente, esse aspecto no qual separa a objetividade da subjetividade, se dá devido a medicina se enquadrar dentro do campo das ciências biológicas, onde a finalidade da clínica médica passa a ser a doença e a lesão, ou seja, foca-se na identificação da doença e na causa, onde preocupa-se em remover a causa para que haja a cura da doença. Práticas como essas se tornaram tão banais que acabaram por estabelecer proposições norteadoras para a prática do médico.

Dessa maneira, adentra-se nas teses acerca da medicalização, que, de acordo com Collares e Moysés (1994 p. 25) refere-se:

\footnotetext{
O termo medicalização refere-se ao processo de transformar questões não-médicas, eminentemente de origem social e política, em questões médicas, isto é, tentar encontrar no campo médico as causas e as soluções para problemas dessa natureza. Omite-se que o processo saúde-doença é determinado pela inserção social do indivíduo
}

Assim, Galindo et al. (2016) mencionam que esse processo de medicalização acaba por desconsiderar a história, o contexto e a cultura do sujeito, elencando uma nova dimensão referente ao direito à saúde e a gestão da população, que é enfatizada através das corporações farmacêuticas, a biomedicina e o marketing, que juntos sistematizam uma grande rede de saberpoder que perpassa as formas de pensar, sentir e agir devido o ajustamento de condutas (normal e anormal), gerenciado para a população "em nome da vida" (PALMA E VILAÇA, 2012) e que Foucault chama de "controle dos corpos". 
De acordo com Foucault (1979/1999) no que tange a medicalização, a mesma funciona como um controle social que visa normatizar e padronizar os comportamentos da população. Tais atitudes tornam-se possíveis porque os dispositivos biopolíticos consistem, como advertiu Foucault (1979), em formações de natureza histórica, o que lhes confere, em cada circunstância, uma função estratégica dominante (MITJAVILA, 2002) que se constitui através das incertezas e do medo que a sociedade carrega em relação a eventos futuros de caráter indesejável.

O processo de controle social ou também entendido como adestramento dos corpos, tem como objetivo principal "adestrar" a grande massa da população com intuito de criar sujeitos obedientes e assim discipliná-los. Essa disciplina é caracterizada ainda por Foucault (1979) como um tipo de poder, no qual alinha os indivíduos a triviais objetos e, ao mesmo tempo, instrumentos do seu próprio exercício. Os instrumentos responsáveis pelo êxito do poder disciplinar são o olhar hierárquico, a sanção normalizadora e sua combinação com um procedimento específico (o exame). Assim, nota-se que o poder disciplinar se trata de um fenômeno invisível no qual se pode vigiar sem ser notado, se expressando pelo olhar e exercendo seu controle sobre os corpos, mantendo-os disciplinados (FOUCAULT, 1987).

Assim, ainda de acordo com o autor mencionado anteriormente, o objetivo da disciplina nada mais é que fabricar corpos úteis, por meio de suas técnicas específicas, criando indivíduos “dóceis" a partir do ponto de vista político e socioeconômico, gerando ainda mais lucros para o Estado, sem contestações e/ou reflexões sobre a posição que se encontra o sistema.

\section{Metodologia}

Este trabalho trata-se de um registro teórico-prático, descritivo e qualitativo, referente a experiência de Estágio Básico em Psicologia Clínica, realizado no segundo semestre de 2019, no Centro de Atenção Psicossocial Infanto-Juvenil (CAPSi) da região norte do Brasil.

O grupo participou de nove oficinas, entre os meses de outubro e dezembro, estabelecendo um dia fixo na semana, com o intuito de estabelecer vínculos e acompanhar a evolução dos usuários, famílias e terapeutas. A estratégia foi escolhida devido à proposta da instituição de atender por agendamentos semanais, com os mesmos pacientes até o recebimento da alta. Mas, por se tratar da única instituição da região norte, as demandas são maiores do que a instituição comporta, e a rotatividade é muito grande de participantes.

A logística das oficinas terapêuticas era distribuída por faixas etárias, com duração de aproximadamente uma hora e as atividades mediadas por profissionais da assistência social, pedagogia e enfermagem, intituladas terapeutas. Naquele momento, não havia no quadro de 
funcionários profissionais da psicologia, não ofertando atendimentos individuais ou mediações de oficinas.

De acordo com a dinâmica da instituição, o estágio foi realizado através de observações em oficinas terapêuticas, especificamente com o público adolescente, por se tratar da maior demanda em números e complexidade de diagnósticos ali presentes. E a partir das observações, fossem favoráveis as construções de vínculos que permitissem a troca entre os estagiários, familiares, usuários e profissionais, para que assim fossem levantadas as principais demandas do grupo e posteriormente a elaboração de ações de acordo com os fundamentos teóricos da abordagem histórico-cultural, aspirando a materialização das emoções e vivências do grupo acompanhado, bem como compreender o processo de subjetividade dos adolescentes a partir de um fazer psicológico para além da clínica.

Tabela 1 - Quadro de atividades realizadas

\begin{tabular}{ll}
\hline Encontros & \multicolumn{1}{c}{ Atividades Realizadas } \\
\hline Encontro 1 & $\begin{array}{l}\text { O grupo de estagiários foi apresentado ao } \\
\text { local de estágio e aos funcionários, tomando } \\
\text { conhecimento da dinâmica local e realizando } \\
\text { a primeira observação de uma oficina para } \\
\text { adolescentes. }\end{array}$ \\
& $\begin{array}{l}\text { Na segunda visita realizou-se mais uma } \\
\text { observação em oficinas para entender a } \\
\text { dinâmica grupal dos usuários do lugar. }\end{array}$ \\
& $\begin{array}{l}\text { No terceiro encontro ocorreu mais uma } \\
\text { observação in loco e o início de um } \\
\text { levantamento de dados para a coleta de } \\
\text { informações relacionadas a sexo, idade, data } \\
\text { de admissão, cidade, queixa principal, } \\
\text { diagnóstico, } \\
\text { encaminhamento. medicamentos }\end{array}$ \\
Encontro 3 2 & $\begin{array}{l}\text { Neste encontro deu-se continuidade ao } \\
\text { processo de coleta de dados. }\end{array}$ \\
Encontro 4 & $\begin{array}{l}\text { No quinto encontro o grupo de estagiários } \\
\text { teve uma nova reunião com a coordenação do } \\
\text { local para explicar como seriam realizadas as } \\
\text { oficinas propostas pelos mesmos. }\end{array}$ \\
& \\
&
\end{tabular}


Encontro 6

Encontro 7

Encontro 8

Encontro 9
Houve observação das atividades realizadas pela terapeuta local, práticas de pintura, matemática básica e caça palavras.

No sétimo encontro aconteceu uma exposição de quadros produzidos pelos adolescentes e os mesmos comentaram o que sentiram ao realizar essas pinturas e quais eram seus significados.

Observação in loco, voltada para a interação da terapeuta mediadora para com o grupo de adolescentes.

No último encontro a oficina foi liderada pelos estagiários que realizaram uma dinâmica que consistia em que os participantes se dividissem em duplas e deitassem em uma folha de papel madeira e um desenhasse o corpo do outro. A atividade tinha por objetivo a expressão da subjetividade de cada um para a materialização de seus sofrimentos e angústias.

\section{Resultados e discussões}

O CAPSi se caracteriza como um serviço de assistencialismo de saúde, que visa permutar os hospitais psiquiátricos, fornecendo atendimentos gratuitos e possibilitando o retorno do usuário para a sua casa, assim valorizando a manutenção dos laços familiares e sociais como mantenedores no processo de promoção de saúde. Essa política assistencialista se diferencia como CAPS I, CAPS II, CAPS III, CAPSi e CAPSad, de acordo com os tipos de demanda dos usuários atendidos, da capacidade de atendimento e da faixa etária.

Esses dispositivos, no seu geral, tem como objetivo a oferta de acompanhamento clínico, reinserção social dos usuários pelo acesso ao trabalho, lazer, exercício dos direitos civis, fortalecimento dos vínculos familiares e comunitários, acesso a oficinas terapêuticas, estas últimas com o objetivo de aprimorar o desenvolvimento de crianças e adolescentes no que concerne a problemas neurológicos de aprendizagem, habilidades motoras, concentração, assim como problemas psicológicos e transtornos psíquicos.

Com base nos resultados apreendidos durante o processo de observação in loco, verificou-se que existe um distanciamento entre o serviço ideal e o que é ofertado. Tornando 
viável visualizar a possibilidade de estabelecer uma correlação entre a teoria e a prática. Observou-se que existem contextos por vezes negligenciados por falta de preparo dos profissionais atuantes. As oficinas terapêuticas oferecidas adquirem um caráter mais mecanicista, por se darem de maneira generalizada.

A Psicologia Histórico Cultural acredita veementemente que é necessário que o homem atribua sentido e significado às coisas para que assim elas possam ser trabalhadas e ressignificadas, sendo por isso a importância de atividades que façam sentido e contemplem as reais necessidades de cada um que tem uma trajetória sócio, histórica e cultural peculiar.

Há um déficit de funcionários muito grande, além de pouca estrutura e material de trabalho. Durante o período de observações realizado entre os meses de outubro e novembro, foi possível apreender algumas demandas relacionadas às práticas ofertadas nas oficinas terapêuticas. A primeira dificuldade observada refere-se quanto a divisão dos grupos que compõem as oficinas terapêuticas, feita apenas mediante critério de faixa etária. Com isso, há uma variabilidade de demandas que não são trabalhadas em sua singularidade nas atividades. Dessa forma, as atividades propostas de pintura e caça palavras que deveriam ser destinadas apenas aos usuários com problemas de aprendizagem, não chamam a atenção dos adolescentes que apresentam demandas mais complexas como problemas familiares, ideação e tentativas suicidas, automutilação, histórico de abuso sexual, sendo estas as mais apreendidas nas observações.

Essas atividades, dependendo a quem são destinadas não possibilitam ao indivíduo avançar. Estes se veem obrigados a frequentar as oficinas para assim ter acesso a outros serviços como atendimento psiquiátrico e psicológico. Desta forma, não há como o serviço ser terapêutico se não é procurado por livre e espontânea vontade, por parte do usuário. Outra demanda demasiadamente observada está relacionada aos diagnósticos e medicalização. Há uma necessidade não só dos médicos, mas também da sociedade em geral, de enquadrar as pessoas em sintomas que caracterizem patologias, a fim de manter o controle dos corpos.

Com isto, percebeu-se ao analisar a história de vida de alguns pacientes via prontuário e mediante acesso a informações passadas por terapeutas que já acompanham os usuários há um tempo considerável, que em alguns casos a medicalização não seria necessária, ou então está em dosagem errada, pois muita das vezes são problemas comportamentais, em grande parte, oriundo de problemas sociais e familiares.

O diagnóstico traz consigo estereótipos patologizantes, havendo assim o aniquilamento da identidade e subjetividade daquele indivíduo que é enquadrado em categorias. Muitas vezes durante as observações, os usuários relataram parar o uso da medicação por conta própria, por Barbarói, Santa Cruz do Sul, n. 56, p.<223-245>,jan./jun. 2020 
se sentirem mal durante o uso, aéreos, trêmulos, sonolentos, atrapalhando todo o comportamento e o desempenho em casa e na escola, o que envolve a vida no que concerne ao seu aspecto biopsicossocial.

Nesse sentido, à luz da teoria histórico cultural, tais observações orientaram a experiência do estágio possibilitando verificar que para que a instituição funcione dentro daquilo em que ela se propõe a ofertar, há a necessidade de se inserir algumas práticas para a melhoria das atividades propostas. Sugere-se a contratação de mais profissionais para mediar os grupos terapêuticos, a fim de dividir os grupos, assim como se caracteriza como imprescindível a figura de psicólogos e psiquiatras compondo a equipe.

$\mathrm{Na}$ condição de profissionais, é fundamental a equipe conhecer minuciosamente a política que rege o lugar e o que ela propõe, observando o ambiente e confrontando-o, bem como conscientes do porquê de estar realizando aquele trabalho, a importância do seu papel como mediador e dos objetivos de cada atividade que propõem nas oficinas terapêuticas, sempre visando prioritariamente a promoção de resultados e saltos qualitativos.

E para que isso se materialize, é necessário conhecer o usuário em suas particularidades para assim propor alguma atividade. A Psicologia histórico-cultural parte do pressuposto de que para um trabalho eficaz e qualitativo é necessário primeiramente conhecer o indivíduo que está ali em busca do serviço. Entender e respeitar a sua história, o contexto de onde ele vem, suas dificuldades e limitações, pensando em possíveis formas de crescimento da zona de desenvolvimento real. Só a partir disso é possível preparar um ambiente que promova atividades direcionadas a ele, proporcionando seu avanço.

Concomitante a isso, propõe-se aos profissionais ofertar espaços para a expressão da subjetividade, criatividade e espontaneidade dos usuários. Independente da precariedade do espaço, a defasagem de materiais e funcionários, é necessário por parte da equipe se reinventar diante do que existe, pois o equipamento é o dispositivo que se tem. Em uma perspectiva histórico-cultural seria ideal proporcionar espaços de expressão, suspendendo atividades desprovidas de sentidos e significados, incentivando também a interação entre os usuários, e entre eles e terapeutas. Pensamento e linguagem devem estar atrelados nas oficinas.

Dessa maneira, de acordo com Farias et al. (2016) mesmo que o trabalho esteja imerso em um universo de normas, submissões e precariedades, é preciso atentar-se as manifestações das subjetividades dos envolvidos no processo. Rego (2009) menciona que em relação a promoção de saúde com os usuários do CAPS, é preciso pensar em uma atuação crítica e reflexiva, assim como em um conjunto de habilidades que permitam visualizar estes pacientes na sua singularidade, inseridos no seu contexto histórico-social.

Barbarói, Santa Cruz do Sul, n. 56, p.<223-245>,jan./jun. 2020 
Diante do exposto, compreende-se que a subjetividade vai além ao que é palpável, assim, faz-se necessário refletir sobre o funcionamento das oficinas, desde a elaboração até a prática, pensando em um ambiente coletivo e terapêutico, trabalhando, tencionando a promoção do cuidado individual e integral dos usuários, com o propósito de oferecer um cuidado individual em um ambiente terapêutico saudável, não servindo apenas como entretenimento e/ou diversão (FARIAS et al. 2016).

\section{Considerações finais}

As atividades de cunho teórico-práticas, apesar de essenciais durante o processo formativo profissional, esbarram sempre em algumas limitações. A começar pela dificuldade de literatura comum a abordagem clínica histórico-cultural, em específico a pouca produção teórica no sentido desse estágio, voltada as oficinas terapêuticas. É um aspecto que ao tempo em que dificulta muito, também possibilita a capacidade de inovar e construir outras práticas.

A quantidade de encontros também se apresentou como fator limitante, haja vista que para estabelecer um maior vínculo e proporcionar uma visão mais ampla da realidade como um todo, necessitaria de mais encontros. Sentiu-se a necessidade de acompanhar o grupo por mais tempo, realizar mais intervenções, acompanhar a evolução e receber feedbacks.

A dificuldade com a falta de materiais, já que o espaço dispõe de pouco instrumento de trabalho, também é um fator restritivo. Ademais, salienta-se também a dificuldade de, enquanto alunos, levar outro olhar em um local com hierarquias bem demarcadas, típico das instituições. A imagem do estagiário geralmente está bastante ligada a inexperiência, e entende-se que as vezes a teoria tem que se adaptar a um serviço com falhas. É fator limitante tendo em consideração que muitos não entendem que se tratam de contribuições a fim de acrescentar ao serviço e trazer melhorias, não apenas críticas.

Tendo em vista a importância do CAPSi como dispositivo de consolidação de um novo modelo de saúde mental, esse estudo se faz importante por levantar reflexões baseadas em vivências no tocante ao trabalho desenvolvido neste espaço, a fim de promover um serviço cada vez mais pautado na ética, no respeito e em um compromisso social e político, com vistas a reivindicar o direito das pessoas a um serviço cada vez mais preparado para acolher as necessidades individuais de cada um.

As observações, questionamentos e apontamentos fundamentados teoricamente, têm como objetivo repensar possibilidades de realizar o trabalho clínico mesmo diante da precariedade física do local e escassez de materiais comuns nos serviços públicos, contribuindo também com um olhar científico para questões já cristalizadas e estereotipadas que envolvem Barbarói, Santa Cruz do Sul, n. 56, p.<223-245>,jan./jun. 2020 
o cerne da saúde mental. O embasamento em um referencial teórico viabiliza a reflexão de novas práticas e maneiras de acolher e atender o usuário, aperfeiçoando o serviço ofertado, visando sempre a promoção de saltos qualitativos, possibilitando ao indivíduo que avance.

\title{
UNA PROPUESTA HISTÓRICO-CULTURAL DE PRÁCTICA CLÍNICA: INFORME DE EXPERIENCIA EN TALLERES TERAPÉUTICOS
}

\section{Resumen}

Este trabajo es un registro teórico-práctico, descriptivo y cualitativo, que se refiere a la experiencia de la pasantía básica en psicología clínica, en la Facultad Católica Dom Orione. Lo mismo ocurrió en las instalaciones de un Centro de Atención Psicosocial para Niños y Jóvenes (CAPSi). La pasantía referida se realizó a través de observaciones en talleres terapéuticos, con un público objetivo de adolescentes, cuyo objetivo principal era favorecer el establecimiento de vínculos entre pasantes, mediadores de talleres, usuarios adolescentes y miembros de la familia, elevando las principales demandas expuestas allí y, en consecuencia Desarrollar acciones de acuerdo con los fundamentos teóricos del enfoque histórico-cultural, articulando teoría y práctica, aspirando a materializar las emociones y experiencias del grupo acompañado, así como a comprender el proceso de subjetividad de los adolescentes desde un punto de vista psicológico más allá de la clínica. Durante las observaciones, se entendió que existe una brecha entre el servicio ideal y lo que se ofrece, lo que hace posible la correlación entre la teoría y la práctica del psicólogo dentro de la institución, considerando que es necesario plantear reflexiones respaldadas por experiencias pertinentes a las acciones desarrolladas en estos espacios, cuyo proyecto es un nuevo modelo de salud mental, con el objetivo de promover un servicio cada vez más guiado por la ética, el respeto y el compromiso social y político, con el objetivo de reclamar El derecho de las personas a un servicio cada vez más preparado para satisfacer las necesidades individuales de cada uno, siempre con el objetivo de promover la salud.

Palabras clave: Talleres terapéuticos. Adolescentes Histórico-Cultural.

\section{A HISTORICAL-CULTURAL PROPOSAL OF CLINICAL PRACTICE: EXPERIENCE REPORT IN THERAPEUTIC WORKSHOPS}

\begin{abstract}
This paper is a theoretical-practical, descriptive and qualitative record, referring to the experience of Basic Internship in Clinical Psychology, at Católica Dom Orione College. The same occurred on the premises of a Child and Youth Psychosocial Care Center (CAPSi). The referred internship was carried out through observations in therapeutic workshops, with a target audience of teenagers, whose main purpose was to favor the establishment of bonds between interns, workshop mediators, teenagers users and family members, raising the main demands exposed there, and consequently develop actions according to the theoretical foundations of the historical-cultural approach, articulating theory and practice, aspiring to materialize the emotions and experiences of the accompanied group, as well as understanding the process of subjectivity of teenagers from a psychological way beyond the clinic. During the observations, it was understood that there is a gap between the ideal service and what is offered, making the correlation between theory and practice of the psychologist within the institution feasible, considering that it is necessary to raise reflections supported by experiences pertinent to the actions developed in these spaces, whose project is a new mental health model, with the purpose


of promoting a service increasingly guided by ethics, respect and social and political commitment, with a view to claiming the right of people to a service increasingly prepared to accommodate the individual needs of each one, always aiming at health promotion.

Keywords: Therapeutic Workshops. Teenagers. Historical-Cultural.

\section{REFERÊNCIAS}

AGUIAR, W. M. J. Reflexões a partir da psicologia sócio-histórica sobre a categoria consciência. Cadernos de Pesquisa, n. 110, p. 125-142, 2000. Disponível em: < http://www.scielo.br/scielo.php?pid=S010015742000000200005\&script=sci_abstract\&tlng=p t >. Acesso em: 22 out. 2019.

ALVES, A. M. P.; CASSIM, F. T. R. Sentidos e significados produzidos por adolescentes a respeito da sexualidade: uma pesquisa sócio-histórica. Rev. Educação e Linguagens, v. 6, n. 11, 2017. Disponível em: <

http://www.fecilcam.br/revista/index.php/educacaoelinguagens/article/viewFile/1538/1051 >. Acesso em: 22 out. 2019.

AZEVEDO, C. A mediação da linguagem na construção da Subjetividade. In: ANDRADE, M. S.; NETO, J. C. S. (Orgs.) Análise Institucional - Diferentes Perspectivas de Aprendizagem, São Paulo: Expressão e Arte, 2007.

BERNI, R. I. G. Mediação: O conceito Vygotskyano e suas implicações na prática pedagógica. Simpósio Nacional de Letras e Linguística e I Simpósio Internacional de Letras e Linguística XI, Uberlândia, 2006. Disponível em: < http://www.filologia.org.br/ileel/artigos/artigo_334.pdf >. Acesso em: 15 out. 2019.

BOCK, A. M. B.; GONÇALVES, M. G. M.; FURTADO, O. Psicologia Sócio-Histórica. São Paulo. 3 ed. 2007.

BRÁS, V. M. C. Estudo de casos clínicos à luz do modelo relacional dialógico. Orientador: Dra Ida Lemos. 2013. 158 f. Dissertação (Mestrado em Psicologia Clínica e da Saúde) Universidade do Algarve, Faro, 2013. Disponível em: < https://sapientia.ualg.pt/bitstream/10400.1/6118/1/Relat \%C3\%B3rio\%20Final.pdf >. Acesso em: 05 nov. 2019.

BORTOLANZA, A. M. E; RINGEL, F. Vygotsky e as origens da teoria Histórico-Cultural: Estudo teórico. Educativa, v.19, n.1, p. 1020-1042, 2016. Disponível em: < http://seer.pucgoias.edu.br/index.php/educativa/article/view/5464 >. Acesso em: 10 out. 2019.

CÂMARA JR, J. M. O estruturalismo. ALFA, v. 11, p. 43-88, 1967. Disponível em: <https://periodicos.fclar.unesp.br/alfa/article/view/3298/3025>. Acesso em: 19 nov. 2019.

CASTRO, H. História Social. In: CARDOSO, C. F.; VAINFAS, R. Domínios da História: ensaio de Teoria e Metodologia. Rio de Janeiro: Campus, 1997.

CFP - Conselho Federal de Psicologia. Carta de Serviços sobre Estágios e Serviços-Escola. São Paulo, 2013. Disponível em:<https://site.cfp.org.br/wp-content/uploads/2013/09/carta-deservicos-sobre-estagios-e-servicos-escola12.09-2.pdf> Acesso em: 23 de nov. 2019. 
COLLARES, C. A. L.; MOYSÉS, M. A. A. A Transformação do Espaço Pedagógico em Espaço Clínico (A Patologização da Educação) Série Idéias - FDE. São Paulo, n. 23, p. 2531, 1994.

DALGALARRONDO, P. Psicopatologia e semiologia dos transtornos mentais. 2. ed. Porto Alegre: Artmed, 2008.

DIAS, M. H. S. A psicologia sócio-histórica na clínica: uma concepção atual em psicoterapia. Rev. SPTM, v. 9, n. 1, p. 67-77, 2005. Disponível em < http://www.ipaf.com.br/arquivos/artigos/artigo_m_helena.pdf >. Acesso em: 24 nov. 2019.

FACCI, M. G. D.; TOMIO, N. A. O. Adolescência: uma análise a partir da psicologia sóciohistórica. Rev. Teoria e Prática da Educação, v. 12, n.1, 89-99, 2009. Disponível em: < http://periodicos.uem.br/ojs/index.php/TeorPratEduc/article/view/14059 >. Acesso em: 25 nov. 2019.

FARIAS, I. D.; THOFEHRN, M. B.; ANDRADE, A. P. M.; CARVALHO, L. A.; FERNANDES, H. N.; PORTO, A. R. Oficina terapêutica como expressão da subjetividade. Rev. SMAD, v. 12, n. 3, p. 147-153, 2016. Disponível em: < http://pepsic.bvsalud.org/pdf/smad/v12n3/pt_03.pdf >. Acesso em: 27 nov. 2019.

et al. Oficinas terapêuticas: percepção de trabalhadores dos Centros de Atenção Psicossocial. J Nurs Health, v. 7, n. 3, 2017. Disponível em < https://periodicos.ufpel.edu.br/ojs2/index.php/enfermagem/article/view/10109 >. Acesso em: 27 nov. 2019.

FERREIRA, M. M. A perspectiva sócio-cultural e sua contribuição para a aprendizagem de língua estrangeira: em busca do desenvolvimento. Revista Intercâmbio, v. 21, p. 38-61, 2010. Disponível em: < http://dlm.fflch.usp.br/sites/dlm.fflch.usp.br/files/A\%20PERSPECTIVA\%20S\%C3\%93CIOCULTURAL.pdf >. Acesso em: 20 nov. 2019.

FONTANA, R.; CRUZ, N. A abordagem histórico-cultural. Psicologia e trabalho pedagógico, p. 56-68, 1997.

FOUCAULT, M. Microfísica do poder. Petrópolis: Vozes, 1979.

Vigiar e Punir: Nascimento da prisão. 27 ed. Petrópolis: Vozes, 1987.

Em Defesa da Sociedade. São Paulo: Martins Fontes, 1999.

GALINDO, D. C. G.; LEMOS, F. C. S.; VILELA, R.; GARCIA, B. Medicalização e governo da vida e subjetividades: o mercado da saúde. Estudos e Pesquisas em Psicologia, v. 16, n. 2, p. 346-365, 2016.

GONZÁLEZ-REY, F. O enfoque histórico-cultural e seu sentido para a psicologia clínica: uma reflexão. In. BOCK, A. M. B.; GONÇALVES, M. G. M.; FURTADO, O. (Orgs.) Psicologia sócio-histórica: uma perspectiva crítica em Psicologia, v. 5, p, 193-214, 2001.

Subjetividade e saúde: superando a clínica da patologia. São Paulo: Cortez, 2011.

Barbarói, Santa Cruz do Sul, n. 56, p.<223-245>,jan./jun. 2020 
.; GOULART, D. M.; BEZERRA, M. S. Ação profissional e subjetividade: para além do conceito de intervenção profissional na psicologia. Rev. Educação, v. 39, n. esp, p. 54-65, 2016.

GUEDES, C. R.; NOGUEIRA, I. N.; CAMARGO JR, K. R. A subjetividade como anomalia: contribuições epistemológicas para a crítica do modelo biomédico. Ciência \& Saúde Coletiva, v. 11, n. 4, p. 1093-1103, 2006.

JOENK, I. K. Uma Introdução ao Pensamento de Vygotsky. Rev. Linhas, v.3, n.1, p. 1-12, 2002.

KAHHALE, E. M. P. Psicologia na saúde: em busca de uma leitura crítica e de uma atuação compromissada. In A. M. B. Bock (Org.), A perspectiva sócio-histórica na formação em Psicologia. Petrópolis: Vozes, 2003.

LEAL, E. M.; DELGADO, P. G. G. Clínica e cotidiano: o CAPS como dispositivo de desinstitucionalização. In: Pinheiro R, Guljor AP, Silva Junior AG, Mattos RA, organizadores. Desinstitucionalização da saúde mental: contribuições para estudos avaliativos. Rio de Janeiro: IMS/UERJ. p. 137-54, 2007.

LEONTIEV, A. N. O desenvolvimento do psiquismo. São Paulo: Centauro, 2004. (Texto original publicado em 1978).

LIMA, P. M.; CARVALHO, C. F. C. A psicoterapia Sócio-Histórica. Psicol. Ciência e profissão, v. 33, 2013. Disponível em: <

http://www.scielo.br/scielo.php?script=sci_arttext\&pid=S1414-98932013000500015 >. Acesso em: 15 out. 2019.

LUCCI, M. A. A Proposta de Vygotsky: A psicologia Sócio-Histórica. Professorado, v.10, n. 2, p.1-11, 2006. Disponível em: < https://www.ugr.es/ recfpro/rev102COL2port.pdf >. Acesso em: 16 out. 2019.

MAFUANI, Francisco Alberto. Estágio e sua importância para a formação do universitário. Instituto de Ensino superior de Bauru. 2011. Disponível em: < http://www.iesbpreve.com.b r/base.asp?pag=noticiaintegra.asp\&IDNoticia=1259>. Acesso em: 20 de nov. 2019.

MARANGONI, S. Ludoterapia como um vygotskyano faz, IPAF, 2012.

; AIRES, J. M. Q. A psicologia sócio histórica na formação de psicoterapeutas.

Psicol. Am. Lat., n. 6, 2006. Disponível em: <

http://pepsic.bvsalud.org/scielo.php?script=sci_arttext\&pid=S18

70-350X2006000200014 >. Acesso em: 21 nov. 2019.

MARX, K. Ontologia del Ser social: el trabajo. Buenos Aires:Herramienta, 2004.

.; ENGELS, F. Ideologia Alemã (Feuerbach). 11. ed. Tradução do alemão por José Carlos Brunni e Marco Aurélio Nogueira. São Paulo: Hucitec, 1999. 
MITJAVILA, M. O risco como recurso para a arbitragem social. Tempo Social, v. 14, n. 2, p. 129-145, 2002. Disponível em: <

http://www.scielo.br/scielo.php?pid=S010320702002000200007\&scri

pt=sci_abstract\&tlng=pt >. Acesso em: 23 nov. 2019

MORI, V. D.; GONZÁLEZ-REY, F. A saúde como processo subjetivo: uma reflexão necessária. Psicologia: Teoria e Prática, v. 14, n. 3, p. 140-152, 2012. Disponível em: $<$ http://pepsic.bvsalud.org/scielo.php?script=sci_abstract\&pid=S151636872012000300012\&1 ng=pt\&nrm=iso>. Acesso em: 22 nov. 2019.

NUNES, V. S.; TORRES, M. A.; ZANOTTI, S. V. O psicólogo no CAPS: um estudo sobre oficinas terapêuticas. ECOS - Estudos Contemporâneos da Subjetividade, v. 5, n. 2, p. 135- 146, 2015. Disponível em: <

http://www.periodicoshumanas.uff.br/ecos/article/view/1649 >. Acesso em 23 nov. 2019.

OLIVEIRA. M. K. Vygotsky: Aprendizado e desenvolvimento um processo sócio-histórico. São Paulo: Scipione, 1993.

PALMA, A.; VILAÇA, M. M. Conflitos de interesse na pesquisa, produção e divulgação de medicamentos. Hist. Cienc. Saúde-Manguinhos, Rio de Janeiro, v. 19, n. 3, p. 919-932, 2012. Disponível em: < http://www.scielo.br/scielo.php?script=sci_arttext\&pid=S010459702012000300008 >. Acesso em: 21 nov. 2019

PESSOA, P. S. A subjetividade a partir de Vygotsky: uma apropriação com a linguagem. In.: VII Congreso Internacional de Investigación y Práctica Profesional en Psicología, Faculdade de Psicologia - Universidade de Buenos Aires, Buenos Aires, 2015. Disponível em: < https://www.aacademica.org/000-015/434.pdf >. Acesso em: 01 nov. 2019.

QUINTINO-AIRES, J. M. Psicoterapia Vygotskyana, 2011.

REGO, T. C. Vygotsky: uma perspectiva histórico-cultural da educação. 20 ed. Petrópolis:Vozes, 2009.

SANTOS, A. C.; NÓBREGA, D. O. Dores e delícias em ser estagiária: o estágio na formação em psicologia. Psicologia: Ciência e Profissão, v. 37, n. 2, p. 515-528, 2017. Disponível em: <http://www.scielo.br/scielo.php?pid=S1414-98932017000200515\&script=sci_arttext >. Acesso em: 21 abr. 2020.

SAVIANI, D. Perspectivas marxiana do problema subjetividade-intersubjetividade. In. DUARTE, N. (Org.). Crítica ao fetichismo da individualidade, Campinas: Autores Associados, 2004.

SIRGADO, A. P. A corrente sócio-histórica de psicologia: fundamentos epistemológicos e perspectivas educacionais. Em Aberto, v. 9, n. 48, 1990. Disponível em: < http://www.proiac.uff.br/sites/default/files/documentos/corrente_socio-historica_repeb.pdf >. Acesso em: 29 out. 2019.

TULESKI, S. C. Vygotski: a construção de uma psicologia marxista. 2 ed. Maringá: Eduem, 2008. 
VYGOTSKY, L. S.; LURIA, A. R. Estudos sobre a história do comportamento: símios, homem primitivo e criança. Porto Alegre: Artes Médicas, 1996.

Pensamento e Linguagem. São Paulo: Martins Fontes, 1991.

A formação social da mente. São Paulo: Martins Fontes, 1989.

Data de recebimento: 02/02/2020

Data de aceite: $21 / 05 / 2020$

\section{Sobre os autores:}

Gilson Gomes Coelho é Doutorando em Psicologia pela Universidade Estadual Paulista "Júlio de Mesquita Filho" (UNESP/Assis). Mestre em Psicologia pela Universidade Estadual de Maringá (UEM). Psicólogo pela Universidade Federal de Mato Grosso do Sul (UFMS/ CPAN). Professor da Faculdade Católica Dom Orione (FACDO). Endereço Eletrônico: gilsonpsico@gmail.com

Ana Carolina Carvalho Arruda é Graduanda do curso de Psicologia da Faculdade Católica Dom Orione (FACDO). Endereço Eletrônico: arrudaanac@gmail.com

Anna Lícya Ferreira Carneiro é Graduanda do curso de Psicologia da Faculdade Católica Dom Orione (FACDO). Endereço Eletrônico: annalicya@gmail.com

Eliane Soares Lima é Graduanda do curso de Psicologia da Faculdade Católica Dom Orione (FACDO). Endereço Eletrônico: elianesoli10@gmail.com

João Henrique Oliveira Barros é Graduando do curso de Psicologia da Faculdade Católica Dom Orione (FACDO). Endereço Eletrônico: henriquob@gmail.com 